\title{
Cellular localization of adenylate cyclase in the developing and mature inner ear of the mouse
}

\author{
Gary Zajic ', Matti Anniko ${ }^{2}$ and Jochen Schacht ${ }^{1 . *}$ \\ 'Kresge Hearing Research Institute, University of Michigan, Ann Arhor, MI 48109. U.S.A. and \\ 'Department of Otolurngologl, Karolinska Hospital, and King Gustat V Research Institute. S-I0140I \\ Stockholm. Sweden
}

(Received 6 December 1982: accepted 27 December 1982)

\begin{abstract}
The localization of adenylate cyclase in the developing and mature inner ear of the CBA/CBA mouse. in Shaker-1 and Shaker-2 mutants and in organ culture was determined by a histochemical procedure with adenylyl imidodiphosphate as substrate and $\mathrm{Sr}^{2+}$ as capture ion. Enzymatic activity was associated with cell membranes in stria vascularis and Reissner's membrane but could not be demonstrated in other cochlear structures. In stria vascularis. adenylate cyclase was found on the contraluminal infoldings of marginal cells but not on their luminal surface, while Reissner's membrane showed activity on its endolymphatic surface. Activity was also associated with utricular dark cells. Essentially the same localization but differing in quantitative aspects was observed during development, in organ culture and in the mutant strains. The speculative role of adenylate cyclase in cochlear ion and fluid balance is discussed.
\end{abstract}

Key words: adenylate cyclase; cyclic AMP; inner ear; ion and water balance; histochemical localization.

\section{Introduction}

The function of the adenylate cyclase/cyclic AMP system in the inner ear remains speculative (for a review, see [15]). The major hypothesis, a participation of this physiological control system in the regulation of cochlear fluid and electrolyte balance was prompted by demonstrations of cyclic AMP effects on water and electrolyte fluxes in a variety of epithelia [16]. Consistent with this speculation, stria vascularis, which is considered to be engaged in the formation of endolymph, contains the highest activity of adenylate cyclase in the cochlea [1,5,7]. Further, a correlation between the postnatal maturation of the ionic profile of endolymph and increasing strial adenylate cyclase activity was demonstrated biochemically [5].

Information about the cellular distribution of adenylate cyclase in the cochlea should be of interest since this enzyme has been shown to have a distinct localization in t:ssues that transport ions or water. In the renal collecting duct, for example, the enzyme complex with receptors for vasopressin is located on the basilar cell membrane while changes in water permeability. mediated by cyclic AMP, occur at

\footnotetext{
* To whom correspondence should be addressed.
} 
the luminal plasma membrane [16]. The present study extends our previous investigations of cochlear adenylate cyclase to its morphological localization in the developing and adult normal inner ear using a histochemical technique with adenylyl imidodiphosphate as specific substrate and $\mathrm{Sr}^{2+}$ as capture ion [18]. In addition, the mutants Shaker-1 and Shaker-2, and the developing labyrinth in culture, are further explored as experimental models for the analysis of enzymatic correlates of fluid regulation. The mutants undergo progressive degeneration of stria vascularis and alterations of endolymph composition [2]; the organ culture has demonstrated levels of adenylate cyclase significantly higher than the labyrinth in vivo [4].

\section{Materials and Methods}

Embryonic and 3-4 month old CBA/CBA mice, and 3-6 week old Shaker-1 and Shaker-2 mutants were investigated. Otocysts were studied on the $13 \mathrm{th}, 16 \mathrm{th}, 19 \mathrm{th}$ and 21 st (birth) gestational day (counting the day of the vaginal plug as day one), postnatal inner ears on the $2 \mathrm{nd}, 4 \mathrm{th}, 6$ th and 8 th day after birth (DAB). For organ cultures, otocysts of CBA/CBA were explanted on the 16th gestational day and cultured for six days [6]. At each age three to six inner ears were processed as described below.

5'-Adenylyl imidodiphosphate (AMP-PNP, tetralithium salt), 5'-guanylyl imidodiphosphate (GMP-PNP, sodium salt), 3'-isobutyl-1-methyl-xanthine (IBMX) and vasopressin were purchased from Sigma Chemical Co. (St. Louis, Mo.), glutaraldehyde and osmium tetroxide (EM grade) from Ted Pella Inc. (Tustin, Calif.). All other chemicals were of the highest purity. Distilled, deionized water was used in the preparation of all solutions.

Mice were killed by cervical dislocation, the temporal bone immediately removed, the cochlear and vestibular organs separated and placed in ice-cold Ringer's solution containing $50 \mathrm{mM}$ glucose ( $\mathrm{pH} \mathrm{7.4;320} \mathrm{mOsm)} \mathrm{for} \mathrm{microdissection.} \mathrm{The} \mathrm{histochemi-}$ cal procedure for most parts of this study was as previously described [18]. However, a refined method was developed in the course of the experiments that achieved a better morphological preservation of inner ear tissues. In this procedure, tissues were

Fig. 1. Electron micrograph (EM). Stria vascularis, basal coil. Glutaraldehyde-paraformaldehyde fixation. The cell membranes of marginal cells (MC) contain a large amount of adenylate cyclase precipitate. In one region (open arrow) the whole intercellular space is filled with precipitate. The surface of $M C$ is free of precipitate, as are also the tight junctions (open arrow). $\times 6400$.

Fig. 2. EM. Stria vascularis, basal coil. Glutaraldehyde-paraformaldehyde fixation. Precipitate is found mainly along marginal cell (MC) membranes. Smaller amounts of precipitate occur also intracellularly (asterisk). Precipitate is lacking on MC surfaces and in the tight junctions. $\times 8700$.

Fig. 3. EM. Third coil of the stria vascularis. Glutaraldehyde-paraformaldehyde fixation. The intercellular space between two marginal cells (MC) is filled with precipitate. The tight junction is indicated with an arrow. $\times 7400$.

Fig. 4. EM. Utricular dark cell epithelium. Glutaraldehyde-paraformaldehyde fixation. Basal extensions of dark cell surrounded by basement membrane show reaction product. $\times 7600$. 


\section{. MC Q 13}

$+,-0,0,2,20$

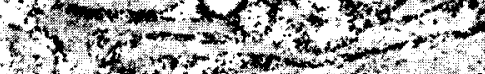

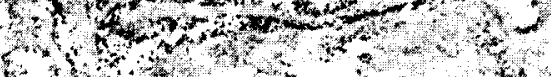

$\lim _{i \rightarrow \infty}$

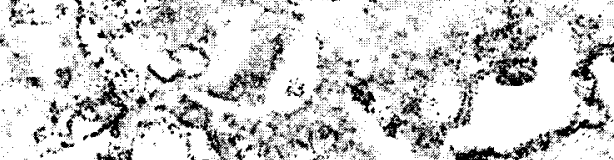

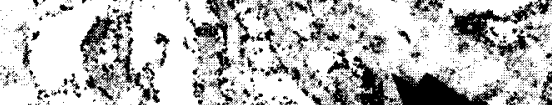

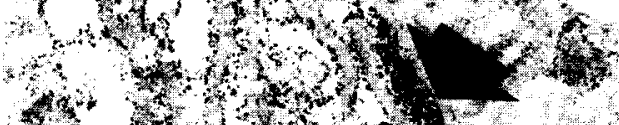

-

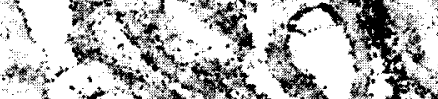

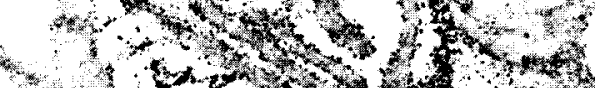

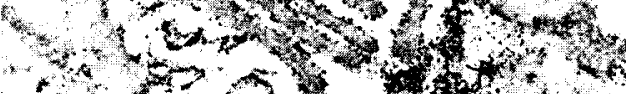

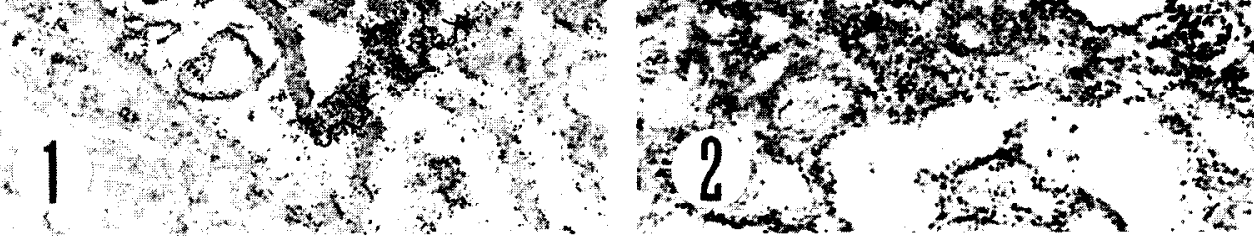

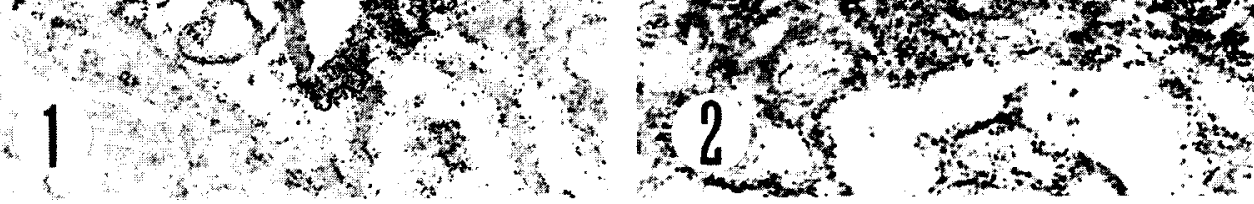

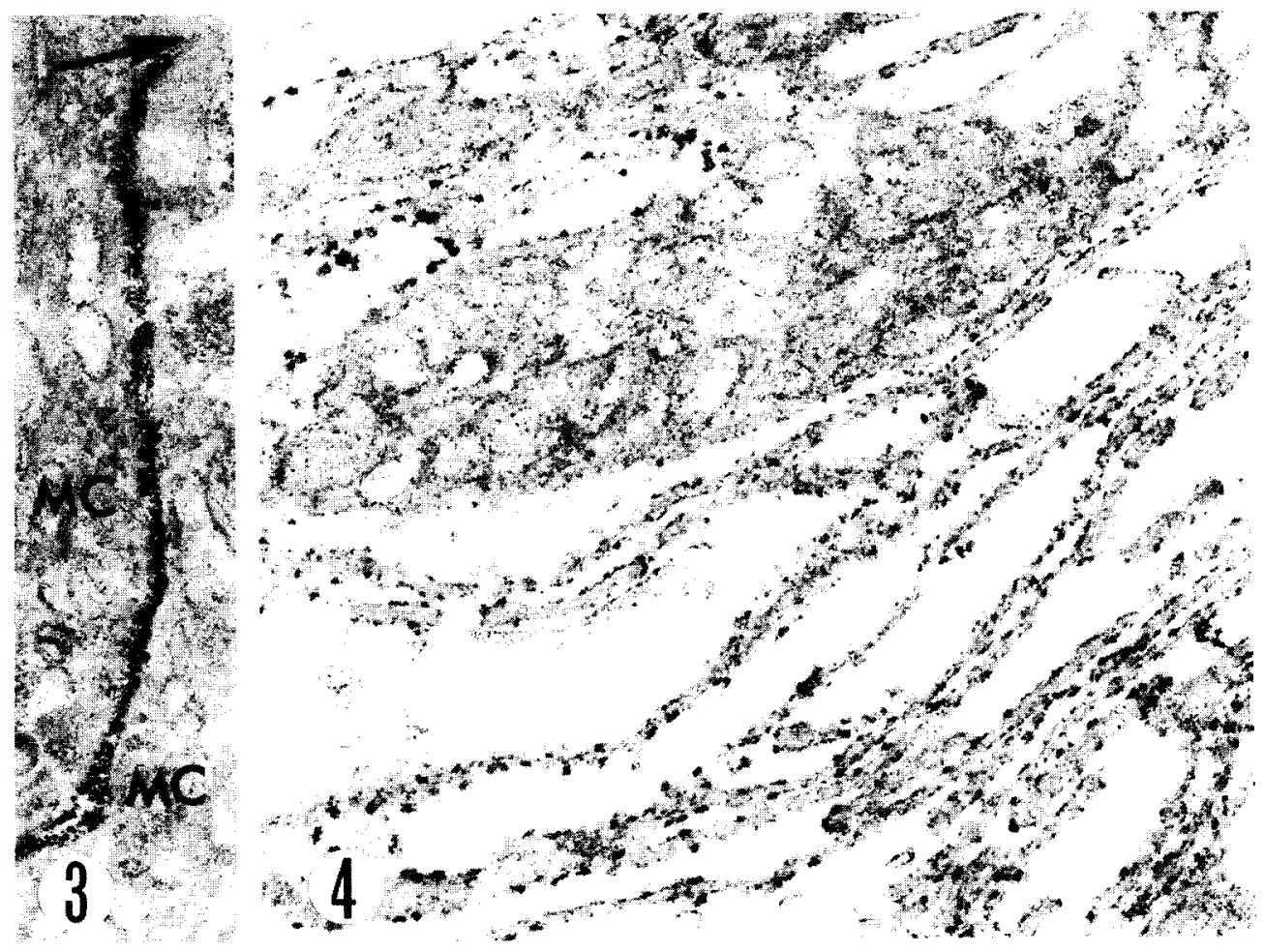


prefixed for $20 \mathrm{~min}$ at $4{ }^{\circ} \mathrm{C}$ in $2 \%$ paraformaldehyde $/ 0.25 \%$ glutaraldehyde in $0.1 \mathrm{M}$ sodium cacodylate $/ 0.05 \mathrm{M} \mathrm{NaCl}, \mathrm{pH} 7.4,300 \mathrm{mOsm}$. Formaldehyde solutions were prepared fresh for each experiment by heating paraformaldehyde in $\mathrm{NaOH}$ until the solution cleared. Prefixation was followed by three washes $(5 \mathrm{~min}$ each) in $0.1 \mathrm{M}$ sodium cacodylate $/ 0.15 \mathrm{~m}$ sucrose, $\mathrm{pH} 7.4$ at $4^{\circ} \mathrm{C}$. The tissues were then incubated for $30 \mathrm{~min}$ at $35^{\circ} \mathrm{C}$ in $0.1 \mathrm{M}$ Tris acetate. $0.15 \mathrm{M}$ sucrose, $4 \mathrm{mM} \mathrm{MgCl}_{2}, 10 \mathrm{mM}$ $\mathrm{SrCl}_{2}, 0.5 \mathrm{mM}$ AMP-PNP, $10 \mu \mathrm{M}$ GMP-PNP, $0.1 \mathrm{mM}$ IBMX and $0.1 \mathrm{mM}$ vasopressin, final $\mathrm{pH}$ adjusted to 8.9 with acetic acid. After incubation the tissues, were rinsed three times with $0.1 \mathrm{M}$ Tris-acetate $/ 0.2 \mathrm{M}$ sucrose, $\mathrm{pH} 8.9$, at $\mathrm{r}(\mathrm{s}) \mathrm{m}$ temperature. Strontium imidodiphosphate was then converted to the lead salt by incubating twice for $\left(5 \mathrm{~min}\right.$ each) in $1 \% \mathrm{~Pb}\left(\mathrm{NO}_{3}\right)_{2} / 0.1 \mathrm{M}$ sucrose $/ 0.1 \mathrm{M}$ Tris acetate, $\mathrm{pH}$ 8.2. This was followed by a rinse in $0.1 \mathrm{M}$ Tris-acetate $/ 0.15 \mathrm{M}$ sucrose. $\mathrm{pH} 8.9$ and a second one in $0.1 \mathrm{M}$ sodium cacodylate/0.15 $\mathrm{M}$ sucrose, $\mathrm{pH} 7.4$. Postfixation was with $1 \% \mathrm{OsO}_{4}$ in $0.1 \mathrm{M}$ sodium cacodylate $/ 50 \mathrm{mM} \mathrm{NaCl}$, pH 7.4 . at $4^{\circ} \mathrm{C}$ for $45 \mathrm{~min}$. Following dehydration in increasing concentrations of ethanol. the tissue was infiltrated with propylene oxide and embedded in Agar 100 resin. dodecenylsuccinicanhydride, nadic methylanhydride and benzyldimethylamine. Sections were cut on a LKB III ultramicrotome and analyzed with a Philips 400 electron microscope.

\section{Results}

Preliminary experiments to determine the localization of adenylate cyclase used two different fixatives: $4 \%$ formaldehyde or $2 \%$ formaldehyde $/ 0.25 \%$ glutaraldehyde in cacodylate buffer. The former resulted in dense precipitation of reaction product. but the overall preservation of ultrastructure was poor. Fewer precipitation granules but localized to the same anatomical areas were seen after paraformaldehyde/glutaraldehyde fixation and the ultrastructure allowed identification of cell types and cell organelles. Adenylate cyclase localization in this study is primarily based on the latter fixation procedure.

\section{Normal adults (CBA/CBA)}

Stria vascularis. Electron dense precipitates occurred along the membranes of the marginal cells, in particular the cell extensions (Figs. 1-3). The tight junctions of the marginal cell toward the endolymphatic space were devoid of precipitates as was

Fig, 5. EM. Epithelial cell (EC) of Reissner's membrane, first coil. Glutaraldehyde-paraformaldehyde fixation. The endolymphatic surface of the EC is covered with precipitate. The nuclear membrane contains a much finer precipitate as do a few of the membrane-bound vesicles in the EC cytoplasm. Very little precipitate occurs on the connective cell (CC) facing the perilymphatic space ( $P$ ). E. endolymphatic space. $\times 8900$.

Fig. 6. EM. Stria vascularis, basal coil. Shaker-1 mouse. Glutaraldehyde-paraformaldehyde-fixed specimen. Precipitate is found on the marginal cell extensions, between these extensions, and on cristae mitochondriales in the extensions (arrows). $\times 2800$. 
E

r.

0

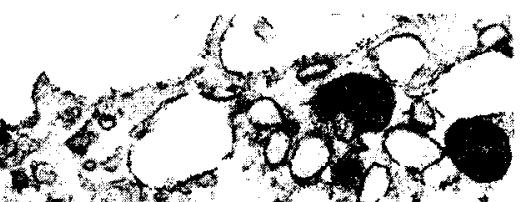

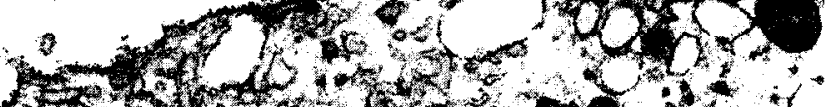

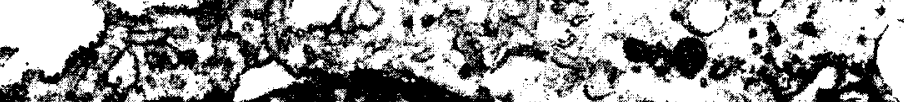

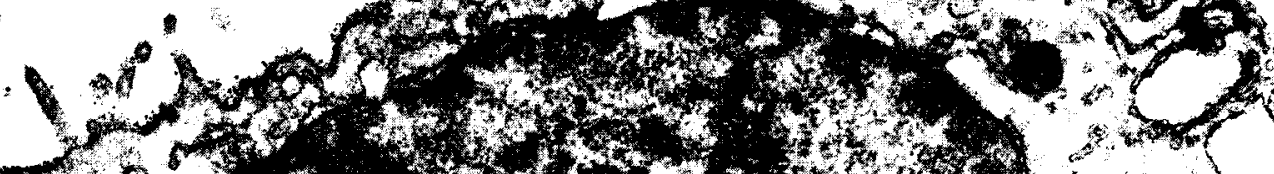

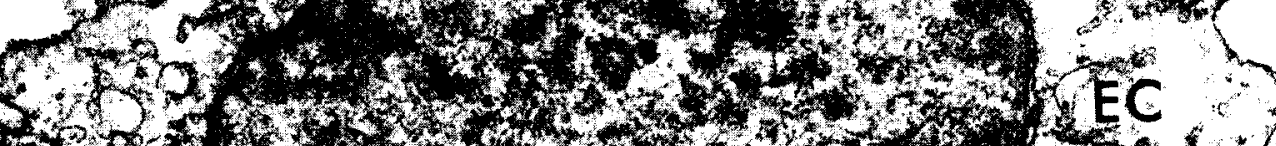

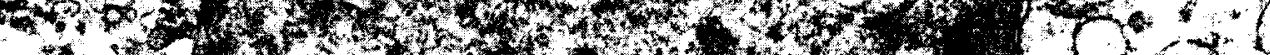

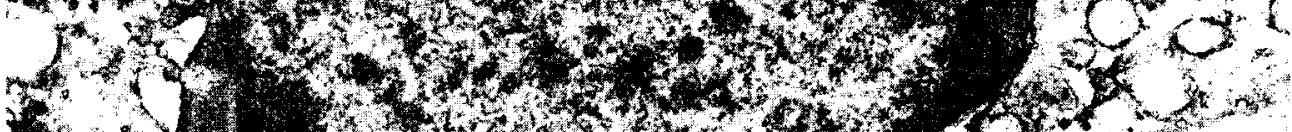

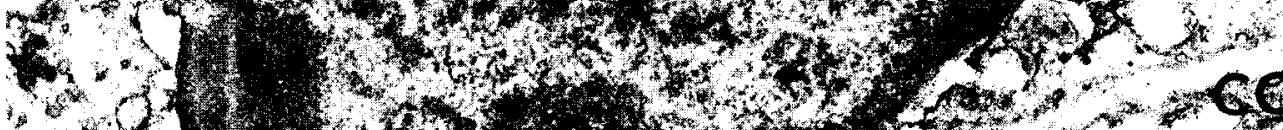

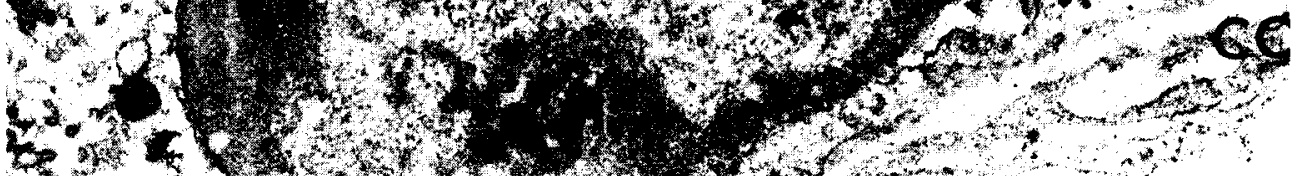

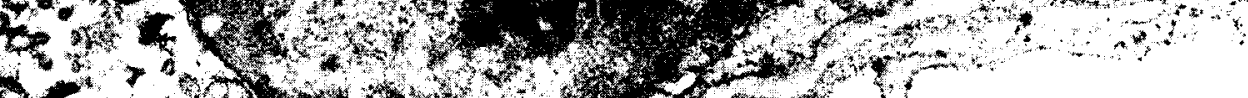

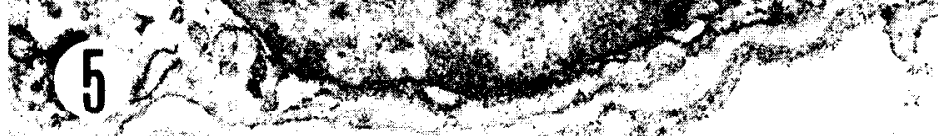




the marginal cell surface toward the scala media (Figs. 1, 2). Precipitates were also found in the intercellular space between marginal cells and intermediate cell interdigitations but never between two adjacent intermediate cells.

The distribution of these precipitates was not homogeneous throughout the stria vascularis. More precipitate was observed along the marginal cell membranes closer to the luminal surface of the scala media but variations in the amount of precipitate precluded quantitation. There was also a suggestive increase of precipitate from the

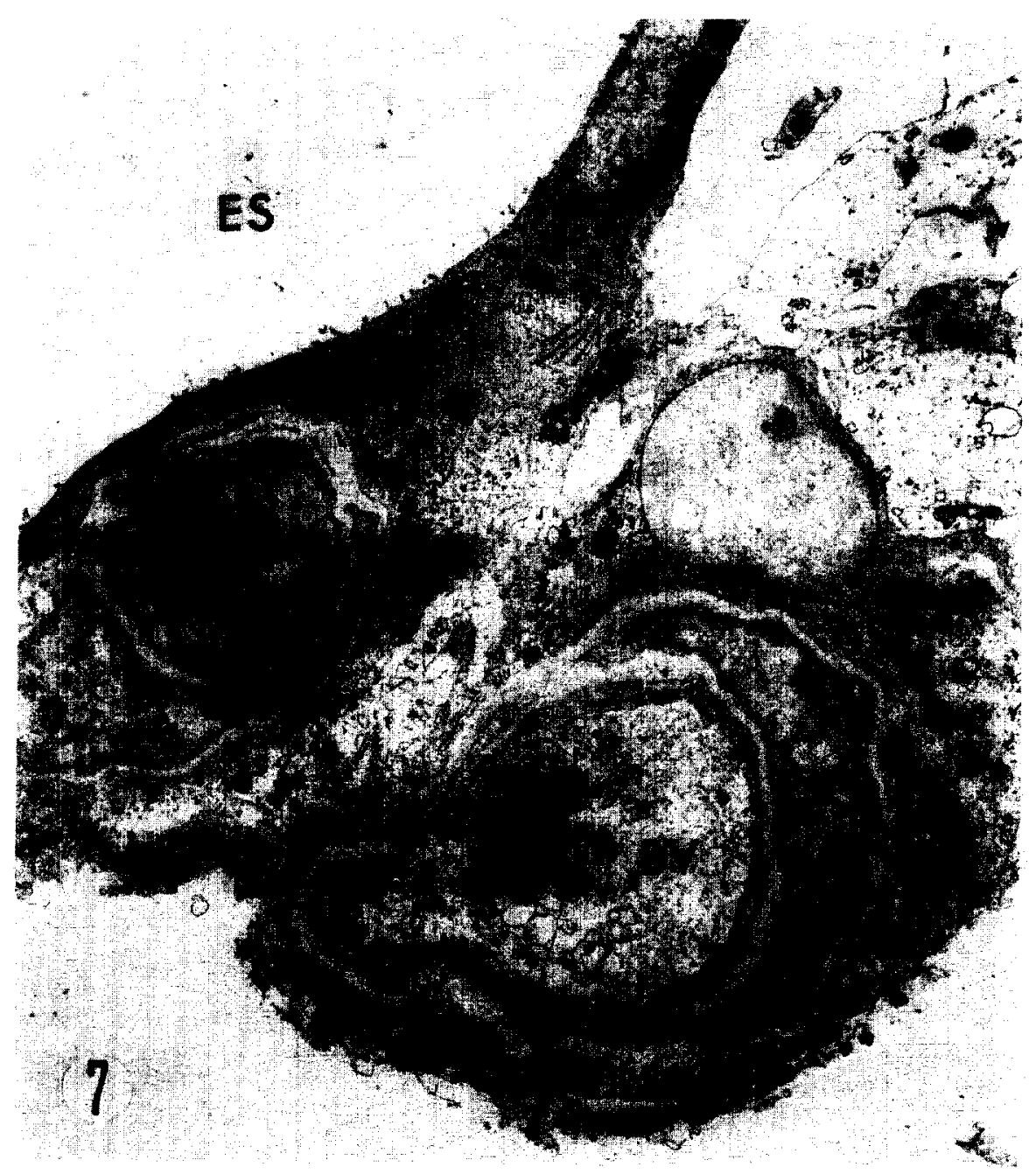

Fig 7. EM. Stria vascularis, basal coil, Shaker-2 mouse. Glutaraldehyde-fixed specimen. Severe degeneration. Type of cells are not possible to determine with great accuracy. BV, blood vessels. ES, endolymphatic space. Precipitate is suspected on the nuclear membranes (arrow) and some mitochondrial cristae. $\times 3200$. 
lateral attachment of Reissner's membrane towards the spiral prominence. The spiral prominence itself, as well as the blood vessels in this area, showed very little precipitate. Throughout stria vascularis, precipitate also occurred on the surfaces of most red blood cells and on both the luminal and the outer surfaces of endothelial cells, known as locations of adenylate cyclase from studies of other tissues.

A fine precipitate was seen on the nuclear membranes of some cells and a few intracellular cisternae, mitochondria, and melanic pigments. These precipitates possibly represent artifacts of $\mathrm{Pb}^{2+}$ capture as described by Ernst [9] for mitochondria.

Interestingly, preliminary investigations of the vestibular system showed reaction product in the dark cell epithelium of the utricle where it was localized to its basal extensions (Fig. 4).

Other cochlear structures. Precipitates were identified mainly as granules of precipitate on the surface of Reissner's membrane facing the scala media. A fine precipitate was also seen along the nuclear membrane and intracellular vesicles (Fig. 5). Other structures of the cochlea lacked electron dense precipitates.

\section{Shaker-1 and Shaker-2 mutants}

Shaker-1. The morphology of the stria vascularis showed no severe degeneration at one month of age and the localization of enzymatic activity was similar to the normal mouse (Fig. 6). It was not possible to quantify the amount of precipitate, but there was a trend towards less precipitate in the mutant stria vascularis than in the stria vascularis of normal animals.

The marginal cells contained electron dense inclusion bodies in the supranuclear region and a clear difference was observed between these inclusion bodies and mitochondria. Many of the inclusions showed an accumulation of precipitate, considerably more than occurring along the cristae mitochondriales.

Shaker-2. The stria vascularis showed a severe morphologic degeneration and it was not possible to identify the types of cells (Fig. 7). The anatomical location of the stria vascularis was occupied by flattened cells with an electron-dense appearance, possibly representing degenerating marginal cells. Electron-dense inclusion hodies occurred in several cells, indicating melanine pigments. Blood vessels, if present. showed varying degrees of morphological degeneration. Precipitates were absent from the membranes of the cells lining the stria vascularis. A few mitochondria showed granules of precipitate along the cristae.

\section{Developing inner ear}

No precipitates were found in embryonic material. On the second DAB the ganglion cells showed a large amount of precipitate on their somal surfaces and around their outgrowing nerves in the region between the ganglion and habenula perforata (basal coil). Stria vascularis of the basal coil of these specimens showed precipitates on red blood cells. Although the network of marginal and intermediate cell extensions was well developed, only minor amounts of precipitate occurred on marginal cell projections in one specimen.

An increasing amount of precipitate was identified along the marginal cell extensions on the 4 th $\mathrm{DAB}$ in the basal and on the 6 th DAB in apical turns. At 8 


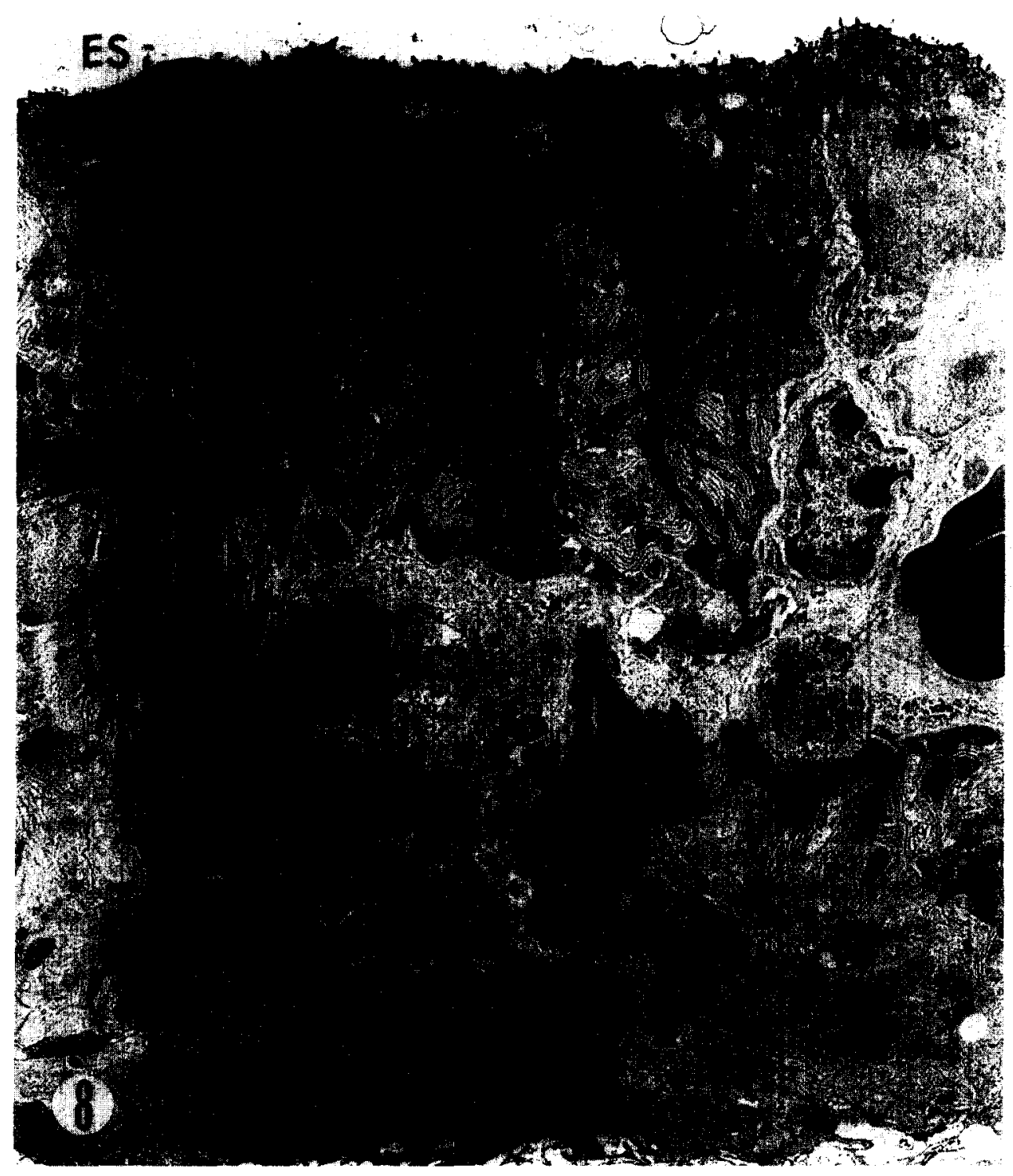

Fig. 8. EM. Stria vascularis, basal coil, 6 DAB. Glutaraldehyde-paraformaldehyde-fixed specimen. The marginal cells (MC) including their cytoplasmic extensions are electron optically much more dense that: intermediate cells (IC) and basal cells. An extensive network of MC and IC extensions has developed. Precipitate (arrows) is found in the intercellular spaces between adjacent MC and MC.IC extensions. ES, endolymphatic space; BV, blood vessel: SL, spiral ligament. $\times 3200$.

Fig. 9. EM. Stria vascularis, basal coil, 16th gestational day inner ear explant cultured in vitro during 6 days. (a) The SV is still immature with only a small number of extensions from the marginal cells (MC) which are columnar. Precipitate occurs between adjacent $\mathrm{MC}$ and along their cell membranes. IC. intermediate cell; ES, endolymphatic space. $\times 6500$. (b) Detail from Fig. 10. Precipitate granules (arrows) along marginal cell membranes. $\times 4800$. (c) Precipitate between two marginal cells. $\times 29000$. 


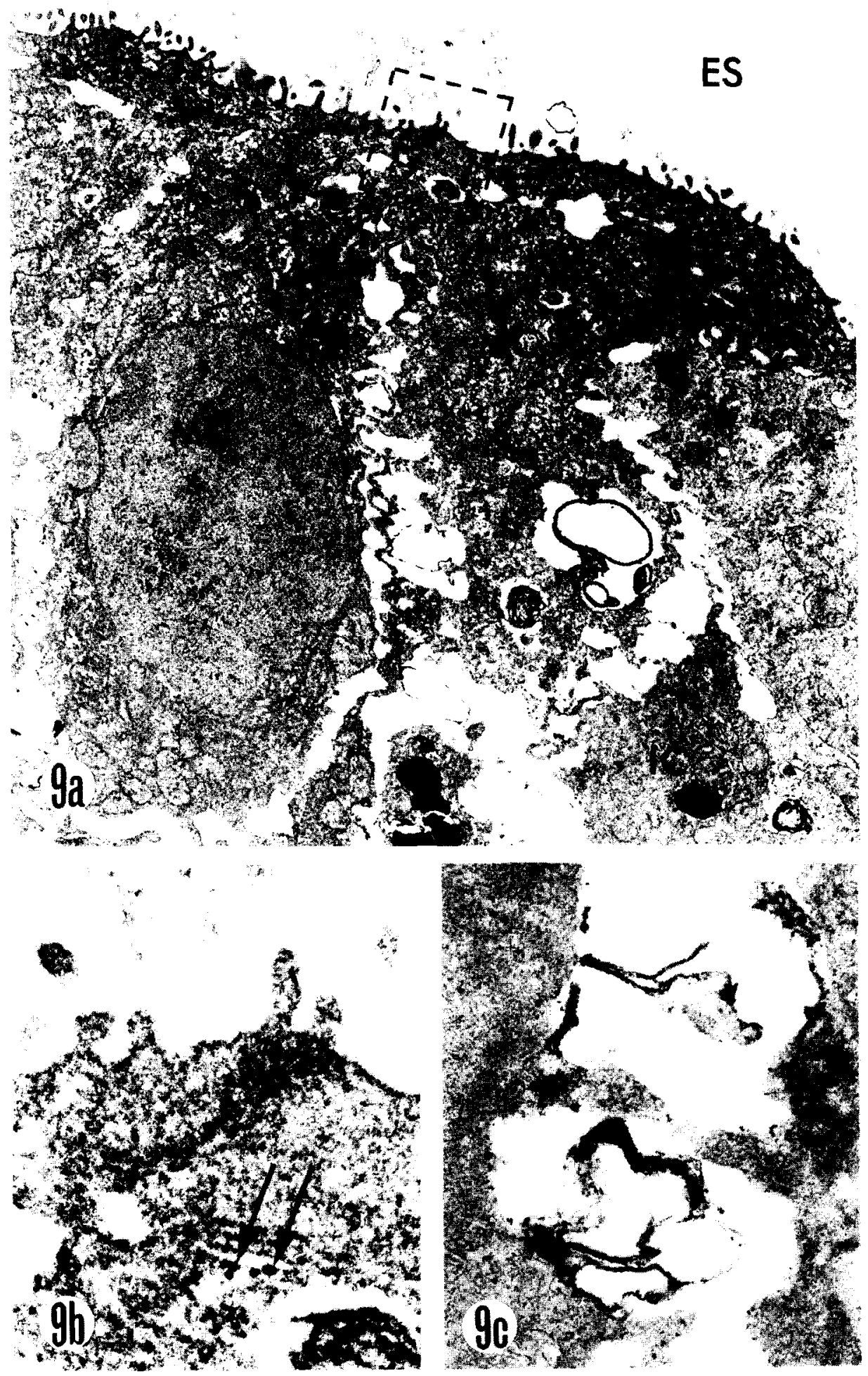


DAB, no difference was seen between the basal and apical parts of the cochlea. The precipitate was initially localized very close to the marginal cell body but from the 6th DAB precipitate was found at all depths of the stria vascularis (Fig. 8). At this time. the precipitate was in close contact with marginal cell extensions, in the intercellular space between two adjacent marginal cells, or between one marginal coll and one intermediate cell extension but never occurred on the cell surface toward the scala media. Precipitate was found in contact with the endothelial lining of strial blood vessels, both at their luminal and outer surfaces.

On the 6th DAB the marginal cells also contained precipitates in the cytoplasm of the supranuclear region close to but not on the outer part of the plasma membrane. These observations were confirmed in specimens from several cochleae.

\section{Organ culture}

At the end of the 6-day culture period the stria vascularis contained all three cell layers but maturation of individual cells was incomplete (approximately corresponding to $2 \mathrm{DAB}$ of in-vivo development). Large intercellular spaces were often seen between cells in all three cell layers but the marginal cells were always in close contact with each other near the scala media. The columnar marginal cells had started to form a network of extensions however. poorly developed. Large amounts of precipitate were found in the intercellular spaces (Figs. 9a and b) and on the marginal cell extensions (Fig. 9c). A large number of mitochondria had precipitate along their cristae. The surface of the marginal cell toward the scala media was always free of precipitate. Other parts of the cochlea in organ culture, e.g. hair cells, cells of the greater epithelial ridge, and Reissner's membrane lacked precipitate.

\section{Discussion}

Highest adenylate cyclase activity in the cochlea is clearly localized to the stria vascularis. The association of adenylate cyclase with certain cell types is quite distinct: at all stages of development it is the marginal cells that contain the enzyme. Interdigitations between adjacent marginal cells or marginal cells and intermediate cells show the highest activity while the endolymphatic surface of the stria is always devoid of precipitate. This lack of localization to the luminal surface of stria vascularis is in disagreement with the report by Duvall et al. [8]. As we discussed and demonstrated previously [15], procedural artifacts inherent in adenylate cyclase histochemistry with $\mathrm{Pb}^{2}+$ as capture ion - as used in their study [8] -- appear to be the cause of this discrepancy.

If we consider the proposed role of the adenylate cyclase/cyclic AMP system in cochlear fluid and electrolyte balance an analogy to the renal tubule and the toad bladder is suggested. While alterations of membrane permeability are expected at the luminal surface of the cells involved, the enzyme is located at the basilar cell membrane and thus accessible to hormones from the circulation or locally released modulators. Cyclic AMP, produced in response to such stimulators, alters specific ion fluxes at the luminal surface by affecting membrane phosphorylation. While 
speculative for the stria vascularis, the histochemical results are consistent with such a scheme as they implicate the marginal cells as the ion and water-transporting epithelium of the stria vascularis.

Reissner's membrane is the only other cochlear structure showing clear enzymatic activity, localized on its endolymphatic surface. With so little information on the physiological role of this membrane, speculation about the function of adenylate cyclase appears premature. Nevertheless, a role of Reissner's membrane in cochlear fluid regulation remains to be considered. Recently, Thalmann [17] demonstrated that cyclic AMP levels were elevated significantly more in Reissner's membrane than in stria vascularis upon stimulation with cholera toxin which is purported to increase endolymphatic volume [10]. A greater increase was observed when cholera toxin was perfused perilymphatically ( 80 -fold) rather than endolymphatically (20-fold). In constrast, strial cyclic AMP levels were elevated more after endolymphatic (4-fold) than after perilymphatic (2-fold) perfusion. Thus, the site of more efficient toxin action is opposite to the location of adenylate cyclase in the cochlea. It should be pointed out that cholera toxin is also a more potent effector of cyclic AMP-dependent ion fluxes in the small intestine when applicd to the luminal surface rather than when applied to the basolateral membrane where adenylate cyclase is localized $[11,16]$.

In the context of these considerations, it seems significant that adenylate cyclase activity is also associated with the utricular dark cells. Generally regarded as the vestibular counterparts of strial marginal cells, these dark cells are thought to constitute a secretory or ion-transporting epithelium.

A major role in the regulation of cochlear fluids and electrolytes has long been discussed for $\mathrm{Na}^{+} / \mathrm{K}^{+}$-ATPase (for a recent review, see [14]). While more widely distributed in the cochlea than adenylate cyclase, its highest activity is found in the contraluminal extensions of the marginal cells [13]. It is interesting that high adenylate cyclase activity is also found histochemically in this location and, in addition, appears restricted to tissues bordering fluid compartments. On the other hand, however, the latter argument should be considered with some caution since the absence of electron dense precipitates does not necessarily mean the absence of the enzyme. In fact, biochemical studies have demonstrated adenylate cyclase widely distributed in cochlear and vestibular tissues [1,5,7]. Fixation of tissues for histochemical studies necessarily represents a compromise between the preservation of ultrastructural integrity and enzymatic activity. Several factors contribute to a selective localization such as the activity of the enzyme, susceptibility to fixation and response to hormonal stimulants. Owing to a report [19] of stimulation of a 'cochlear' adenylate cyclase by vasopressin and isoproterenol we included the former in the present study. Future investigations will have to determine whether histochemical activity in the described locations is indeed enhanced by these agents.

The development of enzymatic activity is in good agreement with our previous biochemical results. The enzyme develops in the marginal cells in parallel with the maturation of endolymph [5]. Furthermore, the differential distribution of activity between basal and apical turns at days 4-6 postnatally is consistent with the differentiation of stria vascularis from base to apex [3]. The possible gradient of 
activity from the attachment of Reissner's membrane to the spiral prominence requires further confirmation before its significance can be assessed.

The studies of neither the mutants nor the organ culture provide clues to the physiology of adenylate cyclase. Although the levels of adenylate cyclase in the two mutant strains appear to correlate well with the intactness of the ionic profile of endolymph [2,3], there is a parallel degeneration of strial morphology. Thus, a correlation between fluid control and adenylate cyclase is too narrow an interpretation since other degenerative effects in stria may affect the composition of endolymph. In organ culture, abnormally high levels of adenylate cyclase are known to develop [4]. These activities are. however, found in their normal locations and, thus, may indicate a lack of regulatory control over the enzyme.

Primarily in culture but also in other specimens, some intracellular precipitates can be observed. Adenylate cyclase is considered an enzyme of the plasma membrane and little is known about any other localizations. Although adenylate cyclase has been demonstrated in the mitochondrial fraction of mammalian cells [12], we cannot be certain about the nature of these precipitates. Artifacts of this and related histochemical procedures include electron dense precipitates in mitochondria and other inclusion bodies $[9,18]$.

In conclusion, our results are consistent with a role of strial adenylate cyclase in the regulation of endolymphatic fluid or electrolyte balance perhaps via a control of ion-specific membrane permeability. However, compounding the difficulties of interpretation are the multi-faceted functions of this enzyme which in addition to fluid regulation include the control of cellular activities such as energy metabolism, secretion, structural organization, or neural responses. In any case, it is intriguing that the most active sites of cochlear (and apparently vestibular) adenylate cyclase are tissues that may be considered to be engaged in transepithelial ion or water transport.

\section{Acknowledgements}

This work was supported by research grant NS-12881 and program project grant NS-05785 from the National Institutes of Health and the Swedish Medical Research Council (12X-720) and the Foundation Tysta Skolan.

\section{References}

1 Ahlström, P., Thaimann, I., Thalmann, R. and Ise, I. (1975): Cyclic AMP and adenylate cyclase in the inner ear. Laryngoscope $85,1241-1258$.

2 Anniko, M. (1982): Specific pathology in the stria vascularis in postnatal progressive genetic inner ear disorder. Hearing Res. 6, 247-258.

3 Anniko, M. and Nordemar, H. (1980): Embryogenesis of the inner ear. IV. Early postnatal maturation of the vestibular dark cells and the stria vascularis of the mammalian inner ear in correlation with the elemental composition of endolymph. Arch. Otorhinolaryngol: 229, 281-288.

4 Anniko, M., Nordemar, H., Spangberg, M.-L. and Schacht, J. (1981): Biochemical studies on the 
embryonic development of the mammalian inner ear in organ culture. Arch. Otorhinularyngot. 230. $237-243$.

5 Anniko, M. Spangberg. M.-L. and Schacht, J. (1981): Adenylate cyclase aetivity in the fetal and early postnatal inner ear of the mouse. Hearing Res. 4, 11-22.

6 Anniko, M., Van De Water, T.R. and Nordemar. H. (1978): Organ culture of the 16ih gestation day mouse labyrinth. A model suggestion for pre- and post-partum development. Acta Otolaryngol. 86. $52-55$.

7 Bagger-Sjöbäck. D., Filipek. C.S. and Schacht. J. (1980): Characteristics and drug responses of cohlear and vestibular adenylate cyclase. Arch. Otorhinolaryngol. 228. 217-222.

8 Duval. A.J. Santi, P.A. and Hukee, M.J. (1980): Cochlear luid balance - A dinical, research overview. Ann. Otol. 89, 335-34l.

9 Ernst, S.A. (1972): Transport adenosine triphosphatase cytochemistry. 11. Cytochemical localization of ouabain-sensitive potassium-dependent phosphatase activity in the secretory epithelium of the avian salt glands. J. Histochem. Cytochem. 20, 23-38.

10 Feldman, A.M. and Brusilow, S.W. (1976): Effects of cholera toxin on cochlear endolymph production: model for endolymphatic hydrops. Proc. Natl. Acad. Sci. U.S.A. 73. 1761-1764.

11 Field. M. Fromm, D. Al-Awqati. Q. and Greenough, W.B. (1972): Effect of cholera enterotixin on ion transport across isolated ileal mucosa. J. Clin. Invest. 51, 796-804.

12 Fine, A.S.. Egnor, R.W., Forrester, E. and Stahl, S.S. (1982): Adenylate cyclase localization in unfixed specimens of rat oral mucosa and isolated mitochondria. J. Histochem. Cytochem. 30, $1171 \ldots 1178$.

13 Kerr, T.P. Ross, M.D. and Ernst, S.A. (1982): Cellular localization of the Na ${ }^{+}$.K-ATPase in the mammalian cochlear duct: significance for fluid balance. Am. J. Otolaryngol. 3, 332 .3.38.

14 Ross, M.D. Ernst, S.A. and Kerr, T.P. (1982): Possible functional roles of $\mathrm{Na}^{+}, \mathrm{K}^{+}$-ATPase in the inner ear and their relevance to Menière's Disease. Am. J. Otolaryngol. 3, 353-360.

15 Schacht, J. (1982): Adenylate cyclase and cochlear fluid balance. Am. J. Otolaryngol. 5. 328. 331.

16 Strewler, G.J. and Orloff, J. (1977): Role of cyclic nucleotides in the transport of water and electrolytes. Adv. Cyc. Nucl. Res. 8. $311-316$.

17 Thalmann, R. (1981): Effects of loop diuretics, mercurials, and other diuretic substances upon the physiological chemistry of the cochlea. Scand. Audiol. S14. 119-129.

18 Zajic. G. and Schacht, J. (1983): Cytochemical demonstration of adenylate cyclase with strontium chloride in the rat pancreas. J. Histochem. Cytochem. 31, 25-28.

19 Zenner. H.P. and Zenner. B. (1979): Vasopressin and isoproterenol activate adenylate cyclase in the guinea pig inner ear. Arch. Otorhinolaryngol. 222, 275--283. 